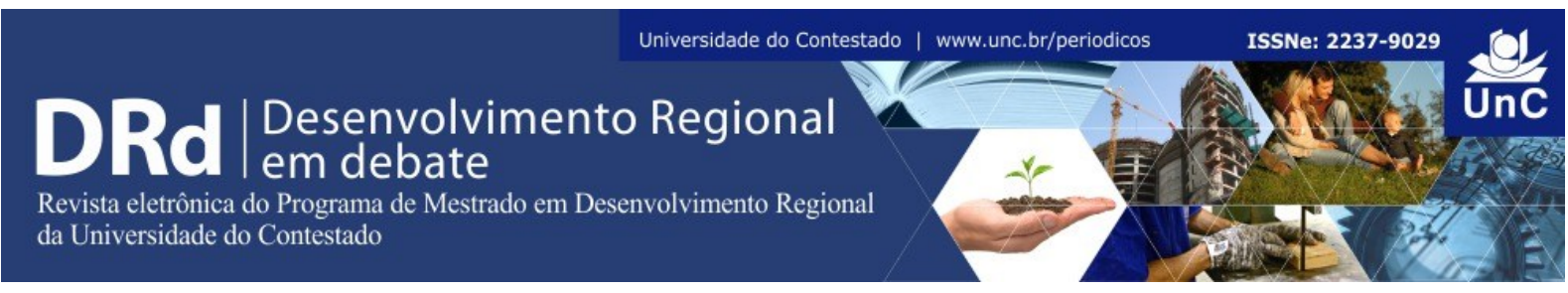

\title{
GESTÃO DA CADEIA DE RECICLAGEM EM REDE: UM ESTUDO DO PROJETO ECOCIDADÃO NO MUNICÍPIO DE CURITIBA ${ }^{1}$
}

Christian Luiz da Silva Gabriel Massao Fugii ${ }^{3}$ Marcos Junior Marini ${ }^{4}$

\begin{abstract}
RESUMO
A gestão inadequada de resíduos gera uma série de problemas ambientais, sociais e econômicos. A Política Nacional de Resíduos Sólidos traz diretrizes para o desenvolvimento de atividades em rede com a finalidade de melhorar a gestão destes resíduos. Há muitas ações no Brasil em trabalhos de redes, como cooperativas e associações de catadores, porém, ainda incipientes e com necessidade de fortalecimento. Neste sentido, a proposta deste trabalho é descrever a gestão de cadeia de reciclagem e suas relações nas atividades de reciclagem no município de Curitiba. A hipótese é que a reciclagem de Curitiba funcionando como uma rede possui a prefeitura no papel central nas ações dentro desta cadeia de recicláveis. O método de pesquisa é dedutiva e aplicada, utilizando o método de pesquisa bibliográfica e de levantamento com análise de conteúdo, bem como a realização de visitas técnicas e entrevista semi-estruturada. Os resultados demonstram que a prefeitura exerce papel de fomentação, manutenção, estruturação e coordenação na rede de reciclagem. Em relação ao Projeto Reciclagem Inclusão Total - ECOCIDADÃO, a prefeitura é um dos principais atores juntamente com Fundação Ação Social (FAS) e a Aliança Empreendedora nas ações desenvolvidas neste projeto. Ainda, há uma dependência da prefeitura para organização desta cadeia, mas o planejamento prevê a sustentabilidade das cooperativas envolvidas no Projeto.
\end{abstract}

Palavras-chaves: Redes. Cooperativas. Cadeia de Reciclagem.

\footnotetext{
${ }^{1}$ Apoio CNPq e Fundação Araucária.

${ }^{2}$ Universidade Tecnológica Federal do Paraná - UTFPR. Bolsista Produtividade CNPq. Programa de Pósgraduação em Tecnologia - PPGTE/ UTFPR. Programa de Pós-graduação em Planejamento e Governança Pública - PGP/ UTFPR. Departamento de Gestão e Economia - DAGEE/ UTFPR. Brasil. E-mail: christianlsilva76@gmail.com.

${ }^{3}$ Universidade Tecnológica Federal do Paraná - UTFPR. Biologo e mestre em tecnologia pela UTFPR (bolsista CAPES). Brasil. E-mail: gabrielfugii@hotmail.com.

${ }^{4}$ Universidade Tecnológica Federal do Paraná - UTFPR. Doutor em Tecnologia e professor do programa de desenvolvimento regional - UTFPR. Brasil. E-mail: marini@utfpr.edu.br.
}

DRd - Desenvolvimento Regional em debate (ISSNe 2237-9029) 


\title{
CHAIN MANAGEMENT RECYCLING NETWORK: A STUDY DESIGN ECOCIDADÃO IN CURITIBA
}

\begin{abstract}
Improper waste management generates a series of environmental, social and economic problems. The National Solid Waste Policy provides guidance for the development of activities in the network in order to improve the management of these wastes. There are many actions in Brazil in work networks such as cooperatives and associations of collectors, however, still incomplete and in need of strengthening. In this sense, the purpose of this paper is to describe the management of the recycling chain and their relationships in recycling activities in the city of Curitiba. The hypothesis is that the recycling of Curitiba functioning as a network has the city on the central role in the actions within this recycling chain. The research method is deductive and applied using the method of literature research and survey with content analysis as well as technical visits and semi-structured interview. The results demonstrate that the city plays a role in fostering, maintenance, structuring and coordinating the recycling network. Regarding Recycling Project Total Inclusion - ECOCIDADÃO, the city is a major player along with Social Action Foundation (FAS) and the Entrepreneurial Alliance actions developed in this project. Still, there is a dependency from the city to the organization of this chain, but planning provides for the sustainability of cooperatives involved in the Project.
\end{abstract}

Keywords: Networks. Cooperatives. Chain of Recycling.

\section{INTRODUÇÃO}

Os resíduos sólidos são um dos maiores desafios para os gestores a nível nacional, estadual e municipal (JACOBI, 2001). Principalmente para o município, por ser o responsável legal pelo seu gerenciamento. Segundo Monteiro et al. (2001) a gestão dos resíduos sólidos não possui, atualmente, a atenção necessária por parte do poder público e consequentemente compromete cada vez mais a saúde da população e os recursos naturais, principalmente o solo e os recursos hídricos.

A industrialização e o desenvolvimento econômico foram acompanhados com o aumento da produção de resíduos e este vem tendo a sua composição alterada, passando de predominantemente orgânico para uma maior quantidade de elementos de difícil degradação (SOUZA; PAULA; SOUZA-PINTO, 2012).

Neste sentido, tornam-se imprescindíveis ações como a reciclagem. Nos termos legais a reciclagem é o processo de transformação dos resíduos envolvendo a alteração de suas propriedades físicas, físico-químicas ou biológicas, com vistas à transformação destes em insumos ou novos produtos. Dentro deste processo os catadores e cooperativas exercem papel fundamental economicamente, ambientalmente e socialmente (SOUZA; PAULA; SOUZAPINTO, 2012). Segundo Baranhuk e Guimarães (2001) o catador de material reciclável existe em Curitiba há mais de 30 anos, enquanto as cooperativas de reciclagem de lixo são recentes no Brasil (MEDEIROS; MACÊDO, 2006). 
A questão de pesquisa é orientada pela necessidade de uma organização da cadeia de reciclagem para transformar este problema urbano em uma alternativa para a gestão urbana. Há muitas ações no Brasil em trabalhos de redes, como cooperativas e associações de catadores, porém, ainda incipientes e com necessidade de fortalecimento. Neste aspecto, a proposta deste trabalho é descrever a gestão de cadeia de reciclagem e suas relações nas atividades de reciclagem no município de Curitiba. O objeto de estudo será o projeto Ecocidadão, o qual envolve o entorno da cadeia de reciclagem neste município. Curitiba possui destaque nacional nas ações de reciclagem. A geração de resíduos no município é atualmente em torno de 1.880 toneladas por dia, das quais 554 toneladas são separadas para a reciclagem. A coleta formal é realizada pelo Programa Lixo que não é Lixo e pelo Câmbio Verde, que recolhem em média 92 toneladas por dia, sendo o restante recolhido pelos catadores de material reciclável (CURITIBA, 2012).

A hipótese é que a reciclagem no município de Curitiba funciona como uma rede possui a prefeitura como papel central nas ações dentro da cadeia de recicláveis. A justificativa de estudar as relações desta rede é conhecer sua estruturação, organização e funcionamento, pois conforme Grippi (2006, p. 31) Curitiba é uma referência no gerenciamento do lixo urbano. Para Andrade (2006) as redes seriam como uma malha de relações, por entre fluxos e nós, compondo um novo arranjo organizacional, que ao incorporar em si dimensões tais como interdependência e integração, responderiam à complexidade dos problemas de gestão e de coordenação das organizações bem como facilitariam à articulação de diferentes atores organizacionais empenhados no processo de gestão.

O artigo está organizado em seis seções, incluindo esta introdução. A segunda seção apresenta a temática das redes, enquanto a terceira seção aborda a cadeia de reciclagem, as cooperativas e a Política Nacional de Resíduos Sólidos. A seção seguinte apresenta os aspectos metodológicos da pesquisa. A quinta seção destina-se à análise, tratando da gestão de resíduos de Curitiba e o Projeto Reciclagem Inclusão Total. Por fim, são apresentadas as considerações finais deste trabalho.

\section{ANÁLISE DE REDES SOCIAIS}

As redes podem ser conceituadas como um conjunto finito de atores (nós) e as relações (laços) existentes entre eles. Para Cruz (2007) o termo vem ganhando novos significados, entre eles a relação de pessoas e organizações que possuem contato entre si e um objetivo comum. Assim, os atores de uma rede são entidades sociais representadas por pessoas, corporações, empresas ou outras unidades sociais. Adicionalmente, os laços representam os relacionamentos e as conexões existentes entre estes atores, estabelecendo a ligação entre um par de atores (WASSERMAN; FAUST, 1994).

Neste cenário, a descrição dos atores implica na identificação dos agentes locais envolvidos (nós) e no mapeamento de suas relações (laços). Com este propósito, o método de Análise de Redes Sociais (ARS) possibilita a visualização e a análise das relações sociais existentes a partir de uma análise sociométrica deste conjunto (WASSERMAN; FAUST, 1994; CRUZ, 2007). 
De forma geral, esses dados podem ser representados em uma matriz sociométrica (sociomatriz) ou uma notação gráfica (sociograma). A sociomatriz é construída a partir da disposição das relações entre os atores em uma matriz bidimensional. O sociograma utiliza a teoria dos grafos para a formação de uma notação gráfica onde cada ponto ou nó representa um ator social, enquanto as linhas correspondem aos laços e as conexões (WASSERMAN; FAUST, 1994; SCOTT, 2000).

Ainda nesta contextualização, ressalta-se que ARS utiliza de teorias e métodos matemáticos para a mensuração de certas propriedades de uma rede social, incluindo o cálculo da densidade da rede, do nível de reciprocidade, bem como da centralidade. Neste sentido, a densidade da rede corresponde ao número de relacionamentos entre os nós, indicando o tamanho da rede e atingindo um valor máximo quando todos os nós são adjacentes (SCOTT, 2000; ALEJANDRO; NORMAN, 2005).

Ademais, a relação de cada nó com os demais representa os vínculos entre os atores sociais. Os fluxos presentes nestas ligações apontam para a direção de cada vínculo, podendo ser unidirecionais ou bidirecionais. Desta forma, o nível de reciprocidade possibilita identificar a simetria entre os atores que formam a rede, demonstrando também o nível da coesão social daquela rede (ALEJANDRO; NORMAN, 2005). Outra análise pode ser obtida por meio da representação do nó mais central da rede (nível de centralidade). Com este propósito, este nó expressa o nível de liderança, prestígio e/ou destaque em relação ao critério analisado na rede social (WASSERMAN; FAUST, 1994; SCOTT, 2000).

Diante do exposto, é importante mencionar que o método de Análise de Redes Sociais (ARS) pode ser utilizado em várias teorias sociais, com a aplicação em diferentes situações e questões que envolvem um conjunto de atores sociais (MARTELETO, 2001). Por exemplo, Teves (2005) trabalhou com a análise de rede e atividade econômica em uma determinada comunidade na Argentina; enquanto Silva et al. (2006) utilizou-se da análise de redes como metodologia de apoio para a análise e discussão da interdisciplinaridade na ciência da informação. Complementarmente, Andion (2003) destaca algumas dimensões para a realização da análise de funcionamento de redes sociais, como: tipologia, densidade, funcionamento e gestão, efetividade na promoção do desenvolvimento local sustentável e abertura para o exterior.

\section{CADEIA DE RECICLAGEM}

Para Calderoni (1999) a cadeia da reciclagem é formada pelos catadores, sucateiros de pequeno e grande porte e a indústria. Corroborando, Aquino, Castilho Junior e Pires (2009) afirmam que existe também o intermediário. Neste sentido, a seguir são apresentadas as definições dos atores participantes desta cadeia:

a) Catador de material reciclável: segundo a classificação brasileira de ocupações (2002), o(a) catador(a) de material reciclável é aquele(a) trabalhador(a) que cata, seleciona e vende materiais recicláveis como papel, papelão, plástico e vidro, bem como materiais ferrosos e não ferrosos e outros materiais reaproveitáveis; 
b) intermediário: é uma organização que realiza a compra e a venda de materiais recicláveis. Entre outras atividades desenvolvidas por intermediários estão: a coleta, a pesagem, a triagem, a trituração, a prensagem, a armazenagem e o transporte de materiais. Apesar da controvérsia, alguns autores afirmam que está a função exercida atualmente pelas associações e cooperativas de catadores, além de empresas com fins lucrativos formais e informais (AQUINO, CASTILHO JUNIOR; PIRES, 2009);

c) Sucateiros: são os donos de ferro velho (DO CARMO, 2009);

d) Indústria recicladora corresponde a organização que realiza a transformação de material reciclável

Reforçou-se a controvérsia sobre o papel das cooperativas e associações, porque a função efetivamente das mesmas não é apenas intermediar, mas há um processo de tratamento e refinamento dos produtos reciclados para redirecionamento para indústria. Algumas avançam, inclusive, para a etapa de indústria retificadora. Contudo, retrata-se que dentro desta cadeia, fica evidente que os menos beneficiados são os catadores (AQUINO, CASTILHO JUNIOR; PIRES, 2009). Segundo Medeiros e Macêdo (2006) estima-se que no Brasil existam 500.000 catadores de materiais recicláveis. Para Carmo (2009), a complexidade da cadeia faz com que os catadores desconheçam completamente os aspectos que a envolvem.

Dentre as alternativas para os catadores obterem melhores benefícios dentro da cadeia da reciclagem, seria a organização deles em empreendimentos autogestionários e a articulação destes em redes ou federações assim obtendo benefícios de ordem social e econômica. (AQUINO; CASTILHO JUNIOR; PIRES, 2009). Uma alternativa é a cooperativa de catadores, que segundo Medeiros e Macêdo (2006) pode desenvolver diferentes ações, visando enfrentar fatores que interferem no processo de negociação de materiais recicláveis, possibilitando competitividade através do aumento da oferta de materiais recicláveis num volume maior que garanta negociação de preços. Trata-se, contudo, de uma cadeia complexa e que depende de uma organização e arranjo institucional que consolide e estruture as atividades e os atores. Silva (2011) ressalta essa questão e exemplifica com a cadeia de PET, uma das mais representativas da reciclagem. A próxima seção posiciona este tema especificamente ao objeto de estudo deste artigo, as redes constituídas por cooperativas envolvendo o contexto da Política Nacional de Resíduos Sólidos.

\section{COOPERATIVAS E A POLÍTICA NACIONAL DE RESÍDUOS SÓLIDOS}

O Plano Nacional de Resíduos Sólidos (PNRS) foi construído com base no processo de consulta pública e audiência pública regional e nacional, junto aos setores especializados, setor público e a sociedade, possuindo estreita relação com outros Planos, como os Planos Nacionais de Mudanças do Clima (PNMC), Plano Nacional de Recursos Hídricos (PNRH), Plano Nacional de Saneamento Básico (Plansab) e Plano de Ação para Produção e Consumo Sustentável (PPCS) (BRASIL, 2012). 
O Plano Nacional de Resíduos Sólidos apresenta propostas e conceitos que refletem em diversos setores da economia, equalizando crescimento econômico e preservação ambiental com desenvolvimento sustentável. Contempla também alternativas de gestão e gerenciamento passíveis de implantação, bem como metas para diferentes cenários, programas, projetos e ações correspondentes (BRASIL, 2012).

É importante destacar que esta política nacional apresenta uma visão sistêmica da gestão dos resíduos sólidos, considerando as diversas variáveis: ambiental, social, cultural, econômica, tecnológica e de saúde pública. Na gestão - voltada para o planejamento - e gerenciamento - aplicação - devem ser observadas as seguintes ordens de prioridade: a não geração, a redução, a reutilização, a reciclagem, o tratamento dos resíduos sólidos e disposição final ambientalmente adequada (BRASIL, 2010).

Por mais que exista um plano e uma legislação que determinem uma ordem de prioridade para a gestão e gerenciamento de resíduos, existe a possibilidade de uma ou mais etapas serem mais relevantes do que outras, não respeitando uma sequência pré-determinada, influenciando indiretamente e/ou diretamente todo o funcionamento do sistema. Assim, conhecer as alternativas tecnológicas de tratamento, bem como conhecer as ações que interferem um sistema integrado é essencial na tomada de decisão acerca de ações estratégicas visando alcançar um futuro desejável, uma vez que a falta de uma gestão adequada gera diversos problemas que afetam diretamente a qualidade de vida do ser humano (ROTH; GARCIAS, 2009).

As cooperativas e associações de catadores de materiais reutilizáveis e recicláveis são abordadas na Política Nacional de Resíduos Sólidos (Lei 12. 305 de 2010). Esta lei incentiva a sua criação, organização, participação e estabelece suas normas. A lei retrata também que o poder público poder instituir medidas indutoras e linhas de financiamento para atender iniciativas de implantação de infraestrutura física e aquisição de equipamentos para as cooperativas ou associações formadas por pessoas físicas de baixa renda.

As cooperativas e associações exercem papel fundamental na logística reversa e na responsabilidade compartilhada pelo ciclo de vida dos produtos, contribuindo para o reaproveitamento dos resíduos sólidos reutilizáveis e recicláveis. Assim, podem trazer benefícios sociais, econômicos e ambientais (SOUZA; PAULA; SOUZA-PINTO, 2012).

Segundo Monteiro et al. (2001) as principais vantagens da utilização de cooperativas de catadores são:

- geração de emprego e renda;

-resgate da cidadania dos catadores;

-redução das despesas com os programas de reciclagem;

- organização do trabalho dos catadores nas ruas evitando problemas na coleta de lixo e armazenamento de materiais em logradouros públicos;

-redução de despesas com a coleta, transferência e disposição final dos resíduos separados pelos catadores. 
Adicionalmente, esses autores afirmam que um dos principais fatores que garantem o fortalecimento e o sucesso de uma cooperativa de catadores é a boa comercialização dos materiais recicláveis. Para tanto, Monteiro et al. (2001) apontam para a necessidade que sejam atendidas algumas condições, como: boa qualidade dos materiais, com baixa contaminação por impurezas e formas adequadas de embalagem/enfardamento; escala de produção e de estocagem, ou seja, ter mercadoria à disposição do comprador; regularidade na produção e/ou entrega ao consumidor final.

Monteiro et al. (2001) ainda chamam a atenção para que uma cooperativa seja fomentada pelo poder público é necessário que possua o seu apoio institucional, visando suprir carências básicas que prejudicam o seu bom desempenho. Os autores destacam entre as principais ações: apoio administrativo e contábil com contratação de profissional que ficará responsável pela gestão da cooperativa; criação de serviço social com a atuação de assistentes sociais junto aos catadores; fornecimento de uniformes e equipamentos de proteção industrial; implantação de cursos de alfabetização para os catadores; implementação de programas de educação ambiental para os catadores; entre outros.

\section{METODOLOGIA}

O método de pesquisa é dedutivo, partindo de um referencial teórico das ações realizadas pela prefeitura de Curitiba na cadeia de matérias recicláveis. A pesquisa é aplicada, e com relação aos objetivos é exploratória e predominantemente descritiva. A pesquisa é exploratória, porque proporciona uma maior familiaridade com um problema por meio do levantamento bibliográfico e documental; é também descritiva, pois tem como propósito descrever as características do fenômeno e estabelecer relações entre variáveis. Estudos exploratório-descritivos combinados têm por objetivo descrever completamente determinado fenômeno (MARCONI; LAKATOS, 2003). Após a utilização do método de pesquisa bibliográfica e documental foi realizado um levantamento com análise de conteúdo.

As pesquisas documental e bibliográfica foram iniciadas com o intuito de realizar a fundamentação teórica do trabalho, bem como o atual estado da arte. Para tanto as primeiras buscas envolveram as palavras-chaves: cadeia de reciclagem; Curitiba; cooperativas de catadores; associações de catadores; Ecocidadão. Foram encontrados documentos da prefeitura municipal de Curitiba que continham informações sobre o Programa Ecocidadão, cooperativas/ associações e catadores de materiais recicláveis, presentes no site do município. Além dos documentos foram encontrados dois artigos: "Avaliação da evolução da renda e qualidade de vida dos catadores de materiais recicláveis de Curitiba, após a implantação do projeto Ecocidadão" (BARANHUK; GUIMARÃES, 2011); e, "Material instrucional de Educação Ambiental: instrumento de gestão pública em Curitiba-PR” (LEME; SILVA, 2010).

Para complementar as informações foi realizado uma entrevista com a coordenadora do Projeto Reciclagem Inclusão Total (ECOCIDADÃO) e parte de sua equipe em outubro de 2013, para atualizar as informações e dados, bem como preencher lacunas e esclarecimento de dúvidas. A entrevista foi guiada a partir de um questionário semi-estruturado, envolvendo os seguintes temas: origem do projeto, vínculo com a prefeitura; organização do processo e participação de cada ator e principais desafios, segundo a percepção da coordenação do 
projeto. A entrevista aconteceu nas dependências da Secretaria Municipal de Meio Ambiente de Curitiba. Posteriormente com a obtenção de todos os dados e informações foram feitas as análises e as considerações retratadas no artigo.

\section{ANÁLISE E DISCUSSÃO DOS RESULTADOS}

Nesta seção do artigo, inicialmente será apresentada uma contextualização do sistema de coleta de resíduos urbanos no município de Curitiba, prosseguindo com uma seção que apresenta o principal objeto deste estudo, o Projeto ECOCIDADÃO, incluindo a análise da sua rede atores sociais.

Curitiba possui um sistema de coleta porta a porta de resíduos sólidos urbanos (RSU), realizada manualmente por catadores e que despejam os resíduos em caminhões com caçambas compactadoras. Em áreas de difícil acesso e desurbanizadas, a prefeitura realiza a coleta convencional indireta, que é realizada através de caçambas estacionárias.

A coleta seletiva é realizada por meio do "Programa lixo que não é lixo" e em pontos de trocas, denominado Programa Câmbio Verde. Este programa acontece quinzenalmente nos logradouros públicos, onde pessoas podem trocar seus materiais potencialmente recicláveis por hortifrútis. A coleta dos recicláveis é realizada por caminhões baús e destinados a Unidade de Valorização de Recicláveis (UVR), a qual está localizada no Município de Campo Magro, sendo administrada pelo Instituto Pró-Cidadania de Curitiba (IPCC), por meio de convênio firmado com este município. Esta unidade é responsável pela triagem e comercialização dos resíduos recicláveis coletados nos "Programa Lixo que não é Lixo" e "Câmbio Verde". Adicionalmente, os recicláveis podem ser destinados ao Projeto Reciclagem Inclusão Total (ECOCIDADÃO), que é realizado nos parques de recepção de recicláveis. O município conta também com as coletas de resíduos tóxicos domiciliares, coleta de resíduos vegetais, coleta de pequenos volumes de resíduos da construção civil e mobiliário inservível, coleta de materiais reaproveitáveis e coleta de cadáveres de animais (CURITIBA, 2010).

No município de Curitiba, é de competência da Secretaria Municipal do Meio Ambiente, criada por meio da Lei Municipal $n^{\circ} 6.817$ de 2 de janeiro de 1986, a gestão dos resíduos sólidos, além de administrar, manter e conservar parques, praças e jardins, cemitérios municipais, implantar e conservar áreas de lazer, realizar levantamento e cadastramento de áreas verdes, fazer o controle das reservas naturais urbanas e fiscalização das mesmas, administrar, manter e preservar o Zoológico, desenvolver pesquisas científicas referentes a fauna e a flora e ainda controlar e fiscalizar a poluição ambiental.

Integra a estrutura da Secretaria Municipal de Meio Ambiente, dois departamentos, que possuem especial destaque na aplicação da política municipal referente aos resíduos sólidos: O Departamento de Limpeza Pública e o Departamento de Pesquisa e Monitoramento. O Departamento de Limpeza Pública tem por atribuição a execução dos serviços de limpeza pública propriamente dita, de forma direta, por execução própria ou indireta, mediante a contratação de serviços, cabendo a este departamento gerenciar, supervisionar e fiscalizar os serviços executados. Esse departamento possui em seu quadro 
120 servidores municipais distribuídos em atividades gerenciais, administrativas e de fiscalização e conta também com 2.352 trabalhadores de empresas terceirizadas.

Ao Departamento de Pesquisa e Monitoramento compete a execução do controle ambiental de forma preventiva, através do licenciamento ambiental de atividades potencialmente poluidoras, ou corretivas, por meio do exercício da fiscalização e aplicação das penalidades previstas na legislação ambiental. Desta forma, o departamento executa a fiscalização da disposição inadequada de resíduos de qualquer natureza, bem como aplica as atividades que couber, a exigência do Plano de Gerenciamento de Resíduos e fiscaliza sua implementação. Compete ainda ao Departamento de Pesquisa e Monitoramento, por meio da Gerência de Educação Ambiental o desenvolvimento das ações de sensibilização e mobilização da população, através dos programas desenvolvidos no âmbito da gestão dos resíduos sólidos.

A Unidade de Valorização de Recicláveis (UVR) opera de segunda-feira a sábado, com a participação de cento e um colaboradores no primeiro turno e setenta e oito no segundo, e está implantada em uma área com vinte e três mil metros quadrados, sendo seis mil metros quadrados de área coberta. Segrega-se nela uma média mensal de 830 toneladas de resíduos (CURITIBA, 2013).

Atualmente, o IPCC possui 36 unidades de valorização de recicláveis particulares credenciadas, para as quais o excedente de material potencialmente reciclável, oriundo do Lixo que não é Lixo e Câmbio Verde, é encaminhado. Estas unidades realizam a triagem dos resíduos e comercialização com aparistas ou diretamente com a indústria de reciclagem (CURITIBA, 2013).

Além disso, os recicláveis podem ser destinados ao Projeto Ecocidadão, que é realizado nos parques de recepção de recicláveis, os quais são espaços dotados de infraestrutura física, administrativa e gerencial para recepção, classificação e venda do material coletado pelos catadores organizados em sistema de associações ou cooperativas, dispondo, ainda, de carrinhos elétricos para a coleta dos resíduos recicláveis para alguns membros do projeto. Atualmente, estão em operação 16 parques, classificando em média 892,28 tonelada/mês de resíduos recicláveis. Sob o ponto de vista socioambiental e de saúde, cem por cento dos catadores associados deixaram de levar seu material para sua moradia, reduzindo a proliferação de vetores de doenças (CURITIBA, 2013).

Ainda nesta contextualização, ressalta-se que com o fim da disposição dos resíduos no Aterro da Caximba, o município passou a dispor seus resíduos nos aterros sanitários particulares, tanto da empresa Essencis Soluções Ambientais SA, situada em Curitiba, bem como da Estre Ambiental SA, situada no Município de Fazenda Rio Grande. A remuneração do serviço de destinação final é feita mensalmente pela quantidade total de resíduos encaminhados para o aterro (CURITIBA, 2013).

No ano de 2007, foi publicado pelo CONRESOL o Edital de Concorrência Pública ${ }^{\circ}$ 001/2007, para implantação de Sistema Integrado de Processamento e Aproveitamento de Resíduos (SIPAR). Esse sistema tinha como objetivo a prestação de serviços de processamento, tratamento e destinação final dos resíduos sólidos urbanos oriundos dos municípios de Almirante Tamandaré, Araucária, Bocaiúva do Sul, Campina Grande do Sul, Campo Largo, Colombo, Contenda, Curitiba, Fazenda Rio Grande, Mandirituba, Pinhais, 
Quatro Barras, Quitandinha e São José dos Pinhais que, na época, integravam este consórcio. O Serviço possuía uma concessão por um período de 20 anos (CURITIBA, 2013).

Segundo informações da prefeitura de Curitiba, o SIPAR tinha como proposta:

\begin{abstract}
Utilizar um sistema composto por um conjunto de tecnologias, capazes de promover o máximo aproveitamento dos resíduos, mediante a aplicação de processos de recuperação e aproveitamento de recicláveis presentes nos resíduos, que não foram separados nos domicílios, aplicação de técnicas de compostagem ou biodigestão visando produzir o composto orgânico com base na parcela orgânica que compõe os resíduos, e ainda a produção do composto derivado de resíduos (CDR), possibilitando o aproveitamento destes materiais para fins energéticos, de forma que a destinação em aterro sanitário esteja limitada à $15 \%$ de rejeitos do processamento (CURITIBA, 2013, p. 127).
\end{abstract}

Após cinco anos desde a publicação do edital de concorrência, o sistema não entrou em operação, devido à propositura de dezenas de demandas judiciais, realizadas em todas as fases do procedimento licitatório: sem uma decisão definida a licitação não pôde prosseguir. Desta forma, em 03/10/2013, o CONRESOL realizou a 24 Assembleia Geral em que definiu por unanimidade pela revogação da Concorrência $n^{0}$ 001/2007, com base nos estudos do Conselho Técnico e do Conselho Fiscal do Consórcio, fundamentando-se no interesse público, oportunidade, conveniência administrativa e fatos supervenientes. Em 2010, foi deflagrado o Credenciamento $\mathrm{n}^{\mathrm{o}} 001 / 2010$ com o propósito de credenciar empresas licenciadas para prestar serviços de destinação final de resíduos sólidos. Dois Aterros Sanitários estão credenciados e devidamente licenciados para atenderem a demanda do CONRESOL. O Município de Curitiba, juntamente com o CONRESOL e com os demais 20 Municípios, vem realizando estudos para o desenvolvimento de uma nova alternativa de gestão de resíduos na região, em concordância com as diretrizes definidas na Política Nacional de Resíduos Sólidos (CURITIBA, 2013).

\title{
PROJETO ECOCIDADÃO A LUZ DOS DOCUMENTOS OFICIAIS
}

O Projeto Reciclagem Inclusão Total, também conhecido como ECOCIDADÃO, surgiu em 2007, como uma iniciativa da prefeitura municipal de Curitiba conjuntamente com um Comitê Gestor formado pela Secretaria Municipal do Meio Ambiente, Fundação de Ação Social, Fundação Avina, Movimento Nacional dos Catadores de Materiais Recicláveis e a Aliança Empreendedora (CURITIBA, 2007 apud LEME; SILVA, 2010). Possui como gestor, a Secretaria Municipal do Meio Ambiente e a Fundação de Ação Social, como principal parceira do projeto.

Este projeto foi implantado como alternativa para aumentar o índice de separação de materiais para a reciclagem, fortalecendo a coleta informal, reconhecendo e incluindo o catador na cadeia de reciclagem (PROJETO RECICLAGEM- INCLUSÃO TOTAL PMC, 2007). Assim, o objetivo é propiciar condições dignas de trabalho, melhorar a sua renda e consequentemente a qualidade de vida dos trabalhadores da coleta informal e de suas moradias (LEME; SILVA, 2010). Ademais, apresenta como diretrizes o desenvolvimento local sustentável, a inclusão social com o desenvolvimento do associativismo/cooperativismo 
e a autogestão pelos catadores de materiais recicláveis informais (CURITIBA, 2007 apud LEME; SILVA, 2010).

O Ecocidadão consiste na implantação de Parques de Recepção de Recicláveis (barracões), em diversas regiões do município. São espaços dotados de infraestrutura física, administrativa e gerencial para recepção, classificação e venda do material coletado pelos catadores organizados em sistema de associações ou cooperativos (BARANHUK; GUIMARÃES, 2011; CURITIBA, 2010).

Cabe ressaltar que desde 2007 já foram implantados 14 parques de recepção de recicláveis, possuindo mais de 350 catadores cadastrados. Está previsto também a assinatura de um convênio com o Banco Nacional de Desenvolvimento Econômico e Social (BNDES), visando a implantação de uma cooperativa central, que ficaria responsável pela comercialização dos materiais recicláveis separados pelas associações e cooperativas. O programa Ecocidadão já conta com uma usina de beneficiamento de pet que foi formalizado pelo convênio e parcerias entre o Instituto Pró-Cidadania - IPCC, a Associação de Catadores de Materiais Reciclável Parceiros do Meio Ambiente - ACAMPA, Fundação Banco do Brasil e Prefeitura Municipal de Curitiba (CURITIBA, 2012).

Com a usina de beneficiamento de pet, a renda das vendas é dividida da seguinte forma: cerca de $70 \%$ é destinada às associações e cooperativas integrantes do Projeto Ecocidadão, com o objetivo de melhorar as condições dos catadores e a aplicação nos programas sociais; $20 \%$ é destinada para manutenção, ampliação, investimentos e formação de capital de giro para compra de material bruto, entre outras despesas da usina; $10 \%$ são destinados ao fundo de reserva do projeto, visando a autossustentabilidade do mesmo (CURITIBA, 2010).

No Projeto também está previsto um programa de formação das equipes operacionais dos Parques de Recepção de Recicláveis e catadores, constituindo uma ação conjunta entre a Secretaria Municipal do Meio Ambiente, entidade executora e entidade selecionada pelo Comitê de Fomento à Reciclagem. Na primeira fase de capacitação foi elaborado um manual com o título de Guia para os Multiplicadores de Catadores de Materiais Recicláveis de Curitiba (GPEC) (CURITIBA, 2009 apud LEME; SILVA, 2010). Para a segunda fase, a Aliança Empreendedora está desenvolvendo uma formação continuada sistemática, com as equipes operacionais e catadores por profissionais contratados por essa ONG (LEME; SILVA, 2011).

De forma geral, o Guia do Projeto Ecocidadão (GPEC, 2009) é um guia de formação em educação ambiental para os multiplicadores que atuam com os catadores de materiais integrantes do projeto. Ele facilita o entendimento para as equipes de multiplicadores de que os princípios de Educação Ambiental estão desenvolvidos na forma de organização do trabalho de catação de materiais recicláveis e perpassam pelos temas de segurança, saúde, trabalho em equipe, e valorização pessoal (LEME; SILVA, 2010). Ademais, o conteúdo sugere atividades nos seguintes aspectos: a valorização pessoal e autoestima do catador, a organização da atividade de coleta (a carrinhada) e a reciclagem, saúde e segurança do catador no trabalho e no trânsito e trabalho em equipe e o associativismo (LEME; SILVA, 2010).

A Aliança Empreendedora é uma organização social sem fins lucrativos, realiza projetos de fomento, integração e apoio ao empreendedorismo comunitário, visando à 
inclusão econômica e social através da geração de trabalho, renda e desenvolvimento local. Logo, é a responsável pela contratação do técnico que estará presente em cada cooperativa/ associação, exercendo diversos papéis, como o suporte contábil e administrativo, esclarecendo dúvidas, entre outras funções. O salário deste profissional é pago pela prefeitura, bem como as despesas com água, luz, aluguel de terreno e ou barracões, bem como fornece os equipamentos como presas, balanças, equipamentos de segurança, carrinhos entre outras ferramentas e equipamentos.

Cabe destacar também, o envolvimento de outras secretarias, como por exemplo, a Secretaria do Governo Municipal, a qual auxilia na verificação do local para a implantação dos parques bem como estabelece o contato com os catadores desta região. A Secretaria Municipal da Comunicação Social realiza toda a parte de divulgação do projeto, a Secretaria Municipal da Educação encaminha os filhos dos trabalhadores dos Parques de Recepção de Recicláveis as escolas, a Secretaria Municipal da Saúde realiza as vacinas contra tétano bem como coloca em dia as demais vacinas, a FAS realiza o tratamento com os indivíduos com problemas com o álcool e outras drogas. Assim, torna-se objetivo da prefeitura, a autogestão por parte dos parques que constituem o Ecocidadão.

Cruz (2012) trabalhou com a Rede de Associações de Carrinheiros, a qual contava com 102 atores em 2011, envolvendo uma estrutura de atores formada por organizações de carrinheiros, organizações do terceiro setor, organizações públicas e iniciativa privada. Entre estes, destacam-se: as Associações e Cooperativas de Carrinheiros, o Instituto Lixo e Cidadania, o Instituto Ambiental do Paraná, a Itaipu Binacional, o Movimento Nacional de Catadores de Materiais Recicláveis, a Sanepar, comerciantes de materiais e indústrias, entre outras. Segundo Cruz (2007), a Rede de Associações de Carrinheiros, corresponde a uma referência aos modelos teóricos de redes para a predominância conceitual dos modelos de análise de redes sociais e de Arranjo Produtivo Local (APL).

Ainda neste debate, uma pesquisa realizada pela Secretaria Municipal do Meio Ambiente (SMMA), em conjunto com a Fundação de Ação Social e a Secretaria Municipal de Saúde, revelou que $41,56 \%$ dos catadores possuíam idade entre 20 e 39 anos e atuavam como catadores há mais de cinco anos, sendo $71,36 \%$ do sexo masculino e $28,64 \%$ do sexo feminino (ERTHAL, 2005 apud LEME; SILVA, 2010).

\section{PROJETO ECOCIDADÃO A PARTIR DA PERCEPÇÃO DA COORDENAÇÃO}

A entrevista com o coordenador do projeto revelou que a proporção de homens e mulheres no projeto Ecocidadão é de $64,4 \%$ eram mulheres, com média de idade aproximada de 39 anos, diferente do realizado pela pesquisa pela SMMA, provavelmente pela diferença temporal dos dados. Atualmente os homens representam 36,6\% dos trabalhadores, com média de idade aproximada de 42 anos. Porém, também se ressalta que o número de mulheres reduz significativamente na época das férias escolares. Outro fator analisado indicou que o número de trabalhadores também é reduzido com os trabalhos temporários no final do ano.

Quanto à jornada de trabalho dentro das instalações, observa-se que começa às 8 horas e termina às 17 horas, com a divisão do pagamento sendo proporcional às horas trabalhadas e 
a quantidade de materiais separados. Em média, estes trabalhadores recebem em torno de mil reais por mês.

Continuando nesta análise, os recicláveis chegam aos parques do Ecocidadão por meio de três vias. A primeira é pelos carrinheiros que fazem coleta porta a porta, a segunda é pela coleta seletiva que envia em média dois caminhões em dois dias da semana, podendo aumentar mediante demanda, ou seja, ocorrer um grande número de cooperados/associados no dia. A terceira via é o encaminhamento de matérias por parte de órgãos públicos e privados.

Os recicláveis são basicamente formados em quatro grandes grupos: papel, plástico, metal e vidro. O papel é o material mais abundante representando cerca de $65 \%$ do material reciclado, seguido do plástico $18 \%$ e metais e vidros representando $8,5 \%$. Destes agrupamentos, os materiais são subdivididos em aproximadamente 35 tipos específicos para a comercialização. Estes materiais são negociados pelas próprias associações/cooperativas de diversos ramos, como de: embalagens, que compram papel; plásticos; vidros; metais e alumínio. Existe também sucata eletrônica que eles acabam trabalhando e negociando, más há uma orientação por parte da prefeitura em não trabalhar com estes materiais por possuírem metais pesados e assim serem potencialmente perigosos à saúde e ao meio ambiente.

Ressalta-se que tanto a usina de beneficiamento quanto a cooperativa central surgiram para eliminar o atravessador, que ainda está presente na cadeia de reciclagem. Este, contudo, é um problema identificado pela coordenadora do projeto, visto que a escolha para negociação é realizada pelas cooperativas e associações acabam negociando no caso do pet com o atravessador ao invés de estarem encaminhando para a usina de beneficiamento, adquirindo assim maior valor, pois, após ser processado em flake possui maior valor comercial. Contudo, acabam não trabalhando com a usina de beneficiamento, pois o atravessador paga a vista, o que não acontece com a usina que paga a prazo.

Analisando especificamente a rede de atores da cadeia de recicláveis a partir do projeto Ecocidadão, observa-se que a prefeitura representada pela Secretaria Municipal de Meio Ambiente, é um dos principais atores neste projeto. Cabe destacar que exerce o papel central (centralidade da rede), atuando na estruturação, manutenção, investimentos, coordenação, na indicação de contatos para a comercialização, bem como na articulação de ações com outras secretarias municipais, órgãos públicos e privados e entidades não governamentais (figura 1).

Com relação às parcerias com outros atores da rede, destacam-se a Fundação Ação Social (FAS), Fundação Avina, Movimento Nacional dos Catadores de Materiais Recicláveis, Aliança Empreendedora, Instituto Pró-Cidadania e Fundação Banco do Brasil. Essas entidades são fundamentais para a implantação do projeto, contribuindo com a manutenção e a aquisição de equipamentos, o que potencializa alternativas tecnológicas de beneficiamento dos recicláveis, assegurando assim, uma melhor qualidade de vida para os participantes.

Nesta análise, é impreterível destacar também que além da prefeitura, os catadores, os carrinheiros de materiais recicláveis e os cooperados, exercem papel fundamental nesta rede social. Esses atores contribuem com participação direta no projeto, ajudando na coleta de recicláveis na cidade e na separação dos materiais reciclados que poderiam estar indo para os aterros, e assim, obviamente, contribuem com a vida útil do aterro e reduzem a extração dos recursos naturais que acabam sendo reutilizados. Logo, este processo representa um ganho 
econômico tanto para os cooperados/associados quanto para a prefeitura e a sociedade. Além disto, implica em ganhos ambientais e sociais.

Figura 1 - Rede de atores na cadeia de recicláveis no município de Curitiba no ano de 2012

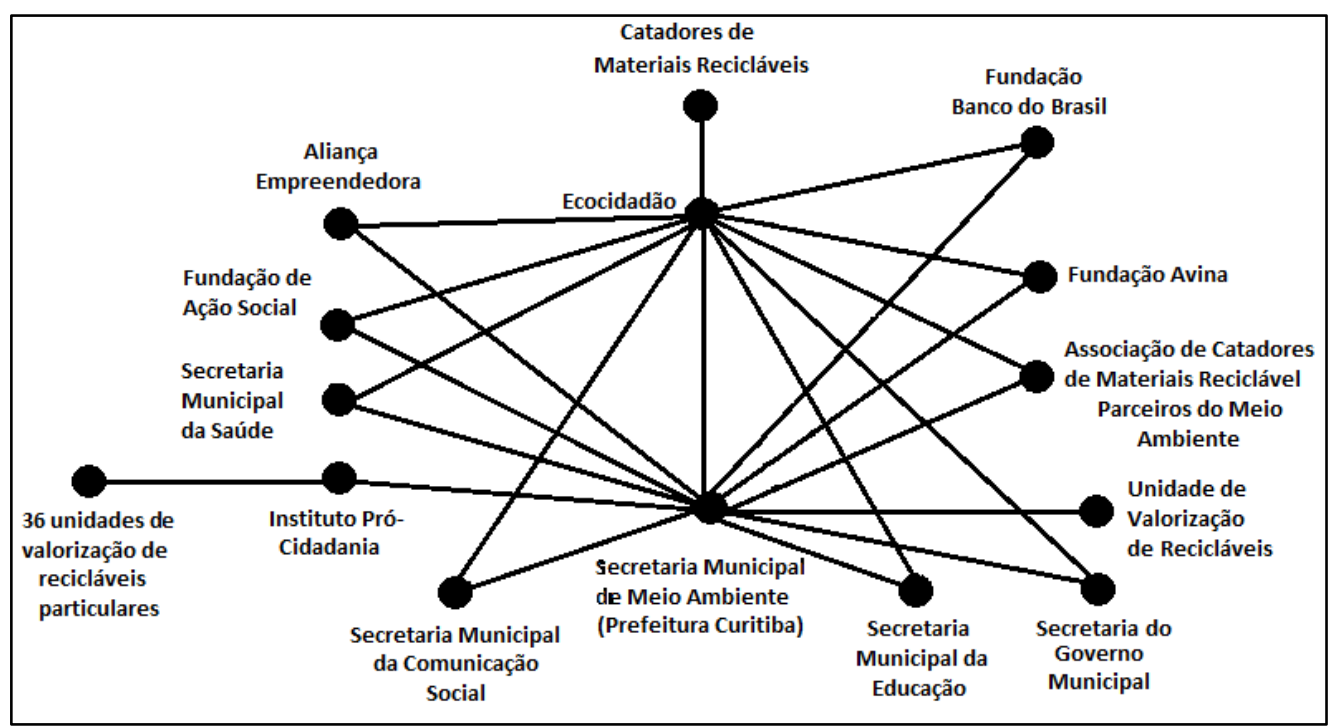

Fonte: Elaborado pelos autores a partir das análises da pesquisa de campo e dos documentos Curitiba (2013); Leme e Silva (2010) Curitiba (2010).

No mais, a pesquisa pode ratificar a compreensão do coordenador do projeto sobre a origem do mesmo, conforme os documentos apresentados na seção anterior, e ressalta que a prefeitura continua fomentando o projeto, mas que se demanda certa autonomia das cooperativas para o seu desenvolvimento. Contudo, há ainda uma dependência da prefeitura por meio do fomento da atividade e da articulação para fortalecimento do projeto como uma alternativa, especialmente pela dificuldade de integração desta etapa da cadeia com os demais elos, o que reforça a necessidade de repensar além do processo de recebimento e reorganização e entrega do material reciclado para um processo de maior reaproveitamento e agregação de valor. Além disso, as necessidades de curto prazo sobrepõem as perspectivas de longo prazo, a exemplo do maior ganho futuro obtido com a venda para usina de beneficiamento que é preterido pelo ganho imediato com a venda, a menor preço, para o atravessador. Isso denota a fragilidade destas organizações e insere o problema sob uma ótica econômica, mas essencialmente social.

\section{CONSIDERAÇÕES FINAIS}

A gestão inadequada de resíduos gera uma série de problemas ambientais, sociais e econômicos. Considerando esta problemática, o artigo buscou descrever os principais atores e sua importância na estruturação, gestão e manutenção dentro da cadeia de reciclagem existente no município de Curitiba. 
As discussões propostas neste artigo confirmam que o município de Curitiba tem uma política de destaque para os recicláveis, ao tratar a questão dos resíduos em consonância com a política nacional, retratada pela Lei 12.305 de 2010, o que possibilita transformar problemas em oportunidades. Com a estruturação dos Parques de Recepção de Recicláveis, o projeto Ecocidadão possibilita o ingresso de catadores informais nas associações ou cooperativas do setor. Logo, as iniciativas possibilitam a inclusão social, além de propiciar condições de trabalho digno, capacitação, melhora na qualidade de vida e aumento de renda.

Ainda se observa uma dependência da prefeitura quanto à organização desta cadeia, mas o planejamento prevê a sustentabilidade futura das cooperativas envolvidas neste projeto. A entrevista com o coordenador do projeto ratificou a percepção dos principais desafios, entre eles a dependência ainda do fomento da prefeitura para garantia do mesmo, e a necessidade de ampliar o planejamento e a estratégia para maior agregação de valor e beneficiamento dos resíduos.

Diante do exposto, confirma-se a hipótese inicial que a reciclagem de Curitiba funciona como uma rede e possui a prefeitura no papel central nas ações dentro desta cadeia de recicláveis. Ademais, salienta-se que o envolvimento e a gestão em rede da cadeia de reciclagem em Curitiba, envolvendo diversos atores no projeto Ecocidadão, serve como exemplo para a estruturação como alternativa para ações e projetos desta cadeia. É importante mencionar também que Curitiba apresenta alternativas, como exemplo, o Programa Câmbio Verde, o Programa Lixo Que Não é Lixo e Unidades de Valorização de Recicláveis. Talvez o maior desafio seja justamente desenvolver a capacidade, destas cooperativas, de empreender de maneira sustentável a partir da melhor organização da cadeia.

Como proposta para trabalhos futuros, torna-se necessário investigar melhor a relação entre os demais atores desta rede principalmente aqueles que a prefeitura possui relação direta como os catadores/carrinheiros, cooperados/associados, assim como os atores que estão envolvidos indiretamente com ela, como os sucateiros, a indústria, entre outros parceiros.

Adicionalmente, as informações destes outros atores poderão servir de base para análises baseadas em softwares ARS, estabelecendo com mais precisão a densidade (o nível de conectividade da rede), a centralidade (onde um ator exerce papel central na rede), bem como a proximidade e a reciprocidade (indicando a capacidade de um ator alcançar os demais nós da rede social).

\section{REFERÊNCIAS}

ALEJANDRO, V. A.; NORMAN, A. G. Manual introdutório à análise de redes sociais. UAEM - Universidad Autonoma Del Estado de México, 2005.

ANDION, C. Análise de Redes e Desenvolvimento Local Sustentável. Revista de Administração Pública, Rio de Janeiro, v. 5, set./out. 2003.

ANDRADE, J. A. Rede de Atores: uma nova forma de gestão das políticas públicas no Brasil? Gestão e Regionalidade, v. 62, p. 10-24, 2006. 
AQUINO, I. F.; CASTILHO JUNIOR., A. B.; PIRES, T. S. L. A organização em rede dos catadores de materiais recicláveis na cadeia produtiva reversa de pós-consumo da região da grande Florianópolis: uma alternativa de agregação de valor. Gestão e Produção (UFSCar), v. 16, p. 10.1590-S0104-5, 2009.

BARANHUK, T. E.S ; GUIMARÃES, A. T. B. Avaliação da evolução da renda e qualidade de vida dos catadores de materiais recicláveis de Curitiba, após a implantação do projeto Ecocidadão. Revista Gestão Pública em Curitiba, v. 2, p. 3-12, 2011.

BRASIL. Ministério do Meio Ambiente. Plano Nacional de Resíduos Sólidos. Brasília, 2012. Disponível em: <http://www.sinir.gov.br/documents/10180/12308/PNRS_

Revisao_Decreto_280812.pdf/e183f0e7-5255-4544-b9fd-15fc779a3657>. Acesso em: 03 jun. $201 \overline{3}$.

Decreto-Lei ${ }^{\circ} 12.305$, de 2 de agosto de 2010. Institui a Política Nacional de Resíduos Sólidos; altera a Lei no 9.605, de 12 de fevereiro de 1998; e dá outras providências.

Diário Oficial da União República Federativa do Brasil, Brasília, DF. 3 ago. 2010. Disponível em: <http://www.planalto. gov.br/ccivil_03/_ato2007-2010/2010/lei/112305.htm>. Acesso em: 7 out. 2012.

CALDERONI, S. Os bilhões perdidos no lixo. 3. ed. São Paulo: Humanistas, 1999.

CARMO, M. S. do. A semântica negativa do lixo como aspecto positivo: um estudo de caso sobre uma associação de recicladores na cidade do Rio de Janeiro, Brasil. Administração

Publica e Gestão Social, v. 1, p. 21-50, 2009.

CONSÓRCIO INTERMUNICIPAL PARA GESTÃO DE RESÍDUOS SÓLIDOS URBANOS. Plano de gerenciamento do tratamento e destinação de resíduos sólidos: versão para consulta pública, Curitiba: Consórcio Intermunicipal, dez. 2007.

CRUZ, J. A.W. Governança de redes, cooperação e desenvolvimento: Estudo de caso em uma rede de associações de coletores de material reciclável. 2007. 180 f. Dissertação (Mestrado). Programa de Pós-Graduação em Administração. Pontifícia Universidade Católica do Paraná, Curitiba, 2007.

A relação entre estrutura de redes sociais e desempenho: um estudo de caso de associações de carrinheiros no Paraná. 2012. 128 f. Tese (Doutorado). Programa de PósGraduação em Administração. Pontifícia Universidade Católica do Paraná, Curitiba, 2012.

CURITIBA. Prefeitura Municipal de Curitiba. Plano Municipal de Saneamento: Gestão Integrada de Resíduos Sólidos Urbanos. Curitiba: 2013. 169p. Disponível em: $<$ http://www.curitiba.pr.gov.br/multimidia/00142058.pdf>. Acesso em: 24 fev. 2014.

. SECRETARIA MUNICIPAL DO MEIO AMBIENTE. Plano de gestão integrada de resíduos sólidos. Curitiba, 2010. 118 p. Disponível em: <http://www.curitiba.pr.gov.br/ multimidia/00082071.pdf>. Acesso em: 20 jun. 2012.

. Nova Usina de pet melhora trabalho de catadores e preserva o meio ambiente. Disponível em: <http://www.curitiba.pr.gov.br/noticias/nova-usina-de-pet-melhora-trabalhode-catadores-e-preserva-o-meio-ambiente/27273>. Acesso em: 3 out. 2012. 
GRIPPI, S. Lixo: reciclagem e sua história: guia para as prefeituras brasileiras. 2. ed. Rio de Janeiro: Interciencia, 2006.

JACOBI, P. R. Meio ambiente urbano e sustentabilidade: alguns elementos para a reflexão. In CAVALCANTI, C. (Org.). Meio ambiente, desenvolvimento sustentável e políticas públicas. São Paulo: Cortez, 2001.

LEME, S. E. G.; SILVA, M. C. Material instrucional de Educação Ambiental: instrumento de gestão pública em Curitiba-PR. Linhas Críticas (UnB), v. 16, p. 327-346, 2010.

MARCONI, M. de A.; LAKATOS, E. M. Fundamentos de metodologia científica. 5. ed. São Paulo: Atlas, 2003.

MARTELETO, R. M. Análise de redes sociais: aplicação nos estudos de transferência da informação. Ciência da Informação, Brasília, v. 30, n.1, p. 71-81, 2001.

MEDEIROS, L. F. R.; MACÊDO, K. B. Catador de material reciclável: uma profissão para além da sobrevivência?. Psicologia e Sociedade, v. 18, p. 29-38, 2006.

MONTEIRO, J. H. P. et al. Manual de Gerenciamento Integrado de resíduos sólidos. Rio de Janeiro : IBAM, 2001. Disponível em: <http://www.resol.com.br/cartilha4/manual.pdf >. Acesso em: 17 jun. 2012.

ROSA, A. V. A.; SOUZA, A. Cooperação coordenada: uma estratégia de crescimento sustentável para pequenas empresas de transporte rodoviários de carga no Brasil. EGEPE Encontro de Estudos sobre Empreendedorismo e Gestão de Pequenas Empresas. PUC-PR, Curitiba, 2005.

ROTH, C. G; GARCIAS, Carlos M. A Influência dos padrões de consumo na geração de resíduos sólidos dentro do sistema urbano. Redes, Santa Cruz do Sul, v. 13, n. 3, p. 5-13, 2009.

SCOTT, John. Social network analysis: a handbook. 2nd ed. London, GB: Sage Publications, 2000.

SILVA, A. B. O. et al. Análise de redes sociais como metodologia de apoio para a discussão da interdisciplinaridade na ciência da informação. Ciência da Informação, v. 35, p. 72-93, 2006.

SILVA, C. L. Arranjo institucional e a cadeia pet: gargalos e potencialidades. Revista Direito Empresarial, Curitiba, v. 8, p. 13-26, 2011.

SOUZA, M. T. S.; PAULA, M. B.; SOUZA-PINTO, H. A importância das cooperativas de reciclagem na consolidação dos canais reversos de resíduos sólidos urbanos pós-consumo.

RAE, v. 52, p. 246-262, 2012.

TEVES, L. Análisis de Redes socials y actividades econômicas em lãs comunidades de Molinos. REDES - Revista hispana para el análisis de redes sociales. v. 9, n.2, 2005. 
WASSERMAN, S.; FAUST, K. Social network analysis: methods and applications. Cambridge: Cambridge University Press, 1994.

Artigo recebido em: 15/08/2014

Artigo aprovado em: 17/03/2015 